\title{
Flipped classroom - Role of Technical Assemblage
}

\author{
Nousheen Savanur $^{1}$, Priya Kulkarni ${ }^{2}$, Poornima Mohanachandran ${ }^{3}$, Daneshwari Kuppasagoudra ${ }^{4}$ \\ ${ }^{1234}$ ekLakshya Innovation Labs, BVB Engineering college campus, Vidyanagar, Hubballi, Karnataka, India \\ ${ }^{1}$ nousheen_s@eklakshya.com \\ 2priya_k@eklakshya.com
}

\begin{abstract}
Recent advances in teaching-learning methodology advocate self-learning and the use of technology to realize the intended outcomes. The Flipped classroom is one such approach, which encourages self-learning and uses technology to automate some of the components of the learning process. While the flipped classroom is found to be very effective, there are challenges in adopting this approach for both the faculty and the learners. At ekLakshya Innovation Labs, Hubballi, Karnataka, India, the flipped classroom is being used for all the training batches. To maximize the learning outcomes a new activity, which is referred as Technical Assemblage, was introduced as a part of the flipped classroom. The expected outcomes from this were improvement in learning for every learner, the ability to formulate and ask questions and the ability to articulate one's understanding. It is likely, that all the learners would not actively participate in the classroom discussion and all may not ask a question. To fill the gap this activity was designed where each learner has an opportunity to participate and ask questions in the presence of an observer. Technical assemblage, in brief, is a wellplanned and co-ordinated explorative discussion in the presence of an observer. In this activity, participants take one of these 3 roles - presenter, audience, or observer. The first step is, to identify topics that were found to be difficult in the pre-class assessments. These topics are then distributed to the learners so that each learner gets an opportunity to present and lead a discussion. While the observer takes responsibility for the scope, the flow of discussion remains fluid. The Technical Assemblage is implemented in multiple training batches and the post-class assessment results of the conventional flipped classroom and proposed method for a particular topic are analyzed. The average score of learners for the conventional method is $69 \%$ and for the proposed method is $79 \%$. Comparing the data of the conventional flipped classroom and proposed method there is a $10 \%$ improvement for the proposed method, which is significant.
\end{abstract}

Keywords: Technical Assemblage, Flipped classroom, Learner centred approach, Open Ended \& Closed Ended questions

\section{Priya Kulkarni}

ekLakshya Innovation Labs, BVB Engineering college campus, Vidyanagar, Hubballi - 580031

priya_k@eklakshya.com

\section{Introduction}

The Flipped classroom offers suggestions for activities both inside and outside of the classroom to encourage deeper learning and greater conceptual understanding [1]. Learning is a process of gaining knowledge and applying the same to solve real-world problems [2]. Conventional learning has involved covering a predefined list of topics through classroom lectures, with learner evaluations towards the completion of the learning process. Time management plays a significant role in balancing the long-term goals of every classroom and bringing into action the immediate educational need of learners [3]. In the flipped classroom, the inclass learning activities such as peer instruction, group discussions, and problem-solving, etc. are proven to be more effective compared to in-person lectures [4], [5], [6]. To maximize the learning outcome, opportunities for reflection should be created. A learner-centred approach is a pedagogical strategy that encourages learners to have increased responsibility for their learning [7], [8].

Different learning approaches need to be examined based on the topic(s) and the learner(s). Self-learning, classroom-style learning, group discussions, problem-solving sessions, and project-based learning are some examples, to name a few. Coming up with the right blend of a selected set of approaches is key to effectiveness while working with the constraints of available time and resources. Any of these approaches may be enabled and enhanced with the use of advanced technology and electronic media. For example in the flipped classroom, online video lectures and online assessments are designed as out of the class activity and group-based problem-solving activities are conducted in the classroom [9].

\section{The conventional flipped classroom}

At ekLakshya, the flipped classroom method is implemented with these 5 steps - (1) watching video lectures, (2) pre-class assessment, (3) classroom discussions and problem-solving, (4) further attempts at the pre-class assessment followed by (5) post class assessments for graded evaluations.

A learner prepares for in-class activity by watching the video lectures, taking the pre-class assessment minimum once, and noting down his/her questions. The in-class activity includes a discussion followed by the specific time allotted for problemsolving. This is followed by more attempts of the pre-class assessment, so that the learners can assess themselves and work on improvements. Details are listed in Table.1 
Table.1: Conventional Flipped classroom

\begin{tabular}{|c|c|c|}
\hline Step 1 & $\begin{array}{l}\text { Watch Video } \\
\text { Lectures }\end{array}$ & $\begin{array}{l}\text { - } \quad \text { Watch any number of times } \\
\text { - } \quad \text { At home or in campus } \\
\text { Access open for entire course }\end{array}$ \\
\hline Step 2 & $\begin{array}{c}\text { Pre-class } \\
\text { Assessment } \\
\text { (first attempt) }\end{array}$ & $\begin{array}{l}\text { - } \quad \text { No, or low passing criteria, But } \\
\text { attempting is mandatory } \\
\text { - } \quad \text { Answers not displayed } \\
\text { - } \quad \text { Done at home or in class }\end{array}$ \\
\hline Step 3 & $\begin{array}{l}\text { Classroom } \\
\text { discussion \& } \\
\text { Problem- } \\
\text { solving }\end{array}$ & $\begin{array}{l}\text { - Start class with the summary of } \\
\text { a topic } \\
\text { - } \\
\text { Address questions from } \\
\text { learners } \\
\text { - } \quad \text { Problem-solving in class }\end{array}$ \\
\hline Step 4 & $\begin{array}{l}\text { Pre-class } \\
\text { Assessment } \\
\text { (further } \\
\text { attempts) }\end{array}$ & $\begin{array}{l}\text { - } \quad \text { No, or low passing criteria, But } \\
\text { attempting is mandatory } \\
\text { - } \quad \text { Answers not displayed } \\
\text { - } \quad \text { Done at home or in class }\end{array}$ \\
\hline Step 5 & $\begin{array}{c}\text { Post-class } \\
\text { Assessment }\end{array}$ & $\begin{array}{ll}\text { - } & \text { Number of attempts: } 01 \\
\text { Done under supervision }\end{array}$ \\
\hline
\end{tabular}

\section{Proposed method}

In the flipped classroom, it is likely, that all learners would not actively participate in the classroom discussion and all may not ask a question. More importantly, all would not get an opportunity to articulate or present their understanding of the concept. To fill this gap, at ekLakshya an activity is designed which is referred as Technical Assemblage where each learner has an opportunity to participate and ask questions in the presence of an observer.

The proposed method involves 6 steps in which 5 steps are the same as the flipped classroom, as already described. Table.2 shows the proposed method. Technical Assemblage is added as a new step after the classroom discussion session. In the technical assemblage, participants take up one of these three roles presenter, audience, and observer as shown in Table 3. The presenter and audience are the learners, while an observer could be a faculty or experienced person from the same field who will be able to assess the discussion.

The key aspects and the flow of Technical assemblage are shown in Fig. 1 and Fig. 2 respectively. The steps involved in Technical assemblage are

1) Selection and distribution of topics: Short listing the topics based on the most difficult questions in the preclass assessments and distributing to the learners.

2) Discussion on the topic: Learner gets an opportunity to lead a discussion, He/she prepares for the discussion on the assigned topic and also has a list of questions for audience interaction.
3) Decision on concluding the session: Observer asses the discussion and decides whether the topic is covered well and can be concluded or needs to be continued.

Table.2: Proposed Method

\begin{tabular}{|c|c|c|}
\hline Step 1 & $\begin{array}{l}\text { Watch Video } \\
\text { Lectures }\end{array}$ & $\begin{array}{l}\text { - } \quad \text { Watch any number of times } \\
\text { - } \quad \text { At home or in campus } \\
\text { Access open for entire course }\end{array}$ \\
\hline Step 2 & $\begin{array}{c}\text { Pre-class } \\
\text { Assessment } \\
\text { (first attempt) }\end{array}$ & $\begin{array}{l}\text { No, or low Passing criteria, } \\
\text { But attempting is mandatory } \\
\text { - } \quad \text { Answers not displayed } \\
\text { Done at home or in class }\end{array}$ \\
\hline Step 3 & $\begin{array}{l}\text { Classroom } \\
\text { discussion \& } \\
\text { Problem- } \\
\text { solving }\end{array}$ & $\begin{array}{l}\text { Start class with the summary } \\
\text { of a topic } \\
\text { - } \quad \text { Address questions from } \\
\text { learners } \\
\text { - } \quad \text { Problem-solving in class }\end{array}$ \\
\hline Step 4 & $\begin{array}{c}\text { Technical } \\
\text { Assemblage }\end{array}$ & $\begin{array}{l}\text { In-class discussion } \\
\text { - } \quad \text { Learner centred } \\
\text { Chose topics based on the } \\
\text { most difficult questions from } \\
\text { the pre-assessments } \\
\text { - Presence of an observer }\end{array}$ \\
\hline Step 5 & $\begin{array}{l}\text { Pre-class } \\
\text { Assessment } \\
\text { (further } \\
\text { attempts) }\end{array}$ & $\begin{array}{l}\text { No, or low Passing criteria, } \\
\text { But attempting is mandatory } \\
\text { - } \quad \text { Answers not displayed } \\
\text { - } \quad \text { Done at home or in class }\end{array}$ \\
\hline Step 6 & $\begin{array}{l}\text { Post-class } \\
\text { Assessment }\end{array}$ & $\begin{array}{ll}\text { - } & \text { Number of attempts: } 01 \\
\text { - } & \text { Done under supervision }\end{array}$ \\
\hline
\end{tabular}

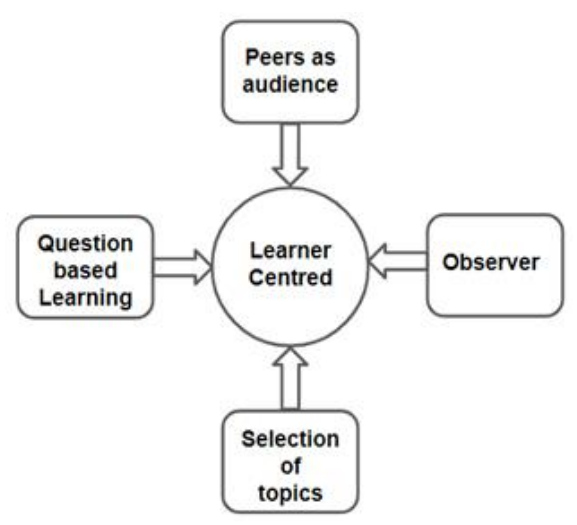

Fig.1: Technical Assemblage-Key aspects

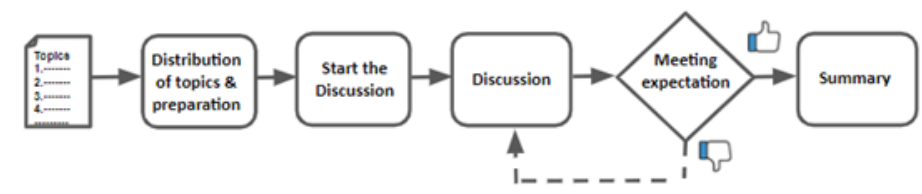

Fig.2: Technical Assemblage-Flow

Table.3: The Role of Presenter, Audience and observer 


\begin{tabular}{|c|c|c|c|}
\hline Step & Presenter & Audience & Observer \\
\hline $\begin{array}{l}\text { 1. Selection and } \\
\text { distribution of } \\
\text { topics }\end{array}$ & ------ & ------- & $\begin{array}{l}\text { Distributes the topics } \\
\text { to each learner }\end{array}$ \\
\hline $\begin{array}{l}\text { 2. Start the } \\
\text { discussion }\end{array}$ & $\begin{array}{l}\text { Initiates and } \\
\text { divides a question } \\
\text { into smaller } \\
\text { chunks }\end{array}$ & ------ & ------ \\
\hline 3. Discussion & $\begin{array}{l}\text { Poses questions to } \\
\text { initiate } \\
\text { participation and } \\
\text { get audience } \\
\text { views } \\
\text { Leads the } \\
\text { discussion with } \\
\text { selection and } \\
\text { elimination } \\
\text { method }\end{array}$ & $\begin{array}{l}\text { Participate in } \\
\text { the } \\
\text { discussion } \\
\text { Bring in new } \\
\text { perspectives } \\
\text { and share } \\
\text { related } \\
\text { information }\end{array}$ & $\begin{array}{l}\text { Ensure the discussion } \\
\text { is within scope. } \\
\text { Use open ended and } \\
\text { close ended questions } \\
\text { to navigate the } \\
\text { discussion }\end{array}$ \\
\hline $\begin{array}{l}\text { 4. Decision on } \\
\text { meeting } \\
\text { expectations }\end{array}$ & ------ & ------ & $\begin{array}{l}\text { Assess the discussion } \\
\text { and check whether the } \\
\text { topic has been covered } \\
\text { well. } \\
\text { Decide to conclude or } \\
\text { continue the } \\
\text { discussion }\end{array}$ \\
\hline 5. Summary & $\begin{array}{l}\text { Summarize and } \\
\text { concludes the } \\
\text { topic }\end{array}$ & ------- & ------- \\
\hline
\end{tabular}

We would like to illustrate with an example, how the topics for Technical Assemblage are chosen and how the scope and flow of discussion is managed by the observer. Listed below are 2 most difficult questions from the CMOS fabrication pre-class assessment. These are selected based on the lowest score obtained in a division or a training batch.

1. Choose the techniques used to isolate active transistors in an Integrated Circuit
a) Field Oxide
b) Channel Stop Implant
c) Shallow Trench Isolation
d) Gate oxide or Thin Oxide

2. Epitaxial layer is deposited to
a) Improve the performance of bipolar devices
b) Prevent latch-up
c) Improve the performance of MOS devices
d) Results in NMOS transistors with lower Vt

The topics for Technical assemblage are chosen based on the above-listed questions such as i. Isolation of active transistor, ii.
Field Oxide, iii. Channel stop implant, iv. Epitaxial layer, v. Latch-up etc.

A possible way to define the scope is given in Fig.3. Exploration is encouraged rather than a rigid timeline and the flow of discussion remains fluid.

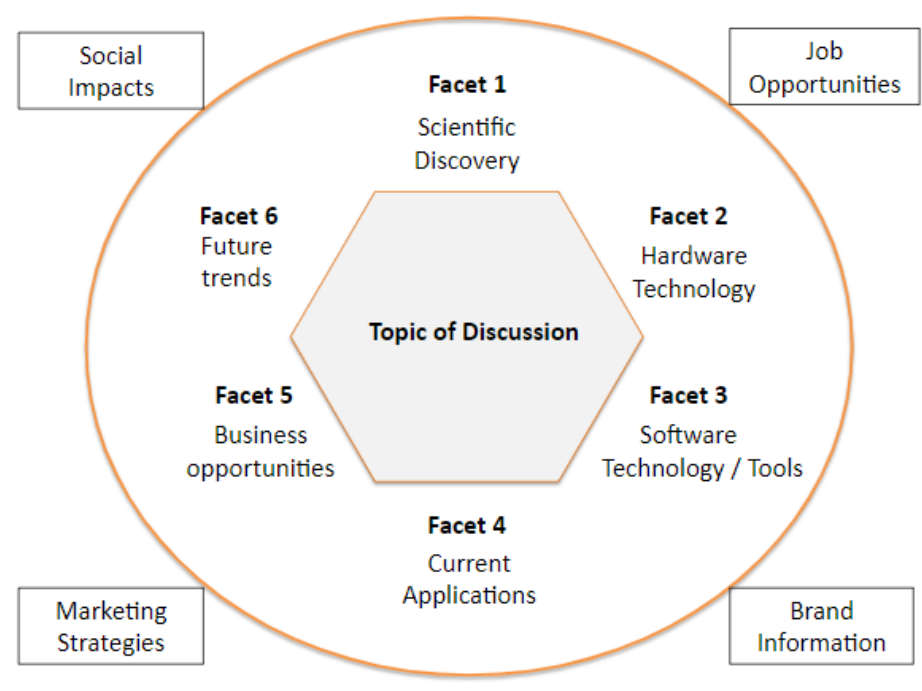

Fig.3: Defining the scope of discussion

As an example let us take evolution of cell phones as the topic of discussion.

Technical assemblage is a platform where the presenter initiates the discussion on the given topic, each learner gets a chance to explain more about the topic by asking questions, and the entire audience is involved in finding the answers. The discussion is intended to cover the six facets of the hexagon mentioned in Fig.3, but not focus on the aspects mentioned outside the circle such as social impacts, job opportunities, brand information, and marketing strategies. This preparation helps the observer to ensure that the discussion continues on the six facets that he/she has prepared upfront. The different facets may be covered in any order during the discussion with the conclusion being done at the end.

The observer also uses open ended and close ended questions to navigate the discussions.

Open-ended questions are used to provide opportunities to encourage discussions, emerge several different views and to develop students' intellectual potential and experience [10]. On the other hand close-ended questions are used to obtain facts and specific pieces of information [11], [12].

\section{Results}

The proposed method was implemented for learner groups from multiple VLSI training batches of varied backgrounds. The results discussed here are from the year 2018 and 2019. A survey was conducted to capture the learning experiences and improvement in assessment results is used for an objective evaluation. 
Learners were requested to grade the experience using five options excellent, good, average, below average, and poor. Responses of excellent and good are considered as favourable outcomes. The results indicate (Fig.4) that more than $90 \%$ of learners found this activity to be helpful in improving their communication skills, knowledge sharing, thinking ability, and getting solutions for their questions.

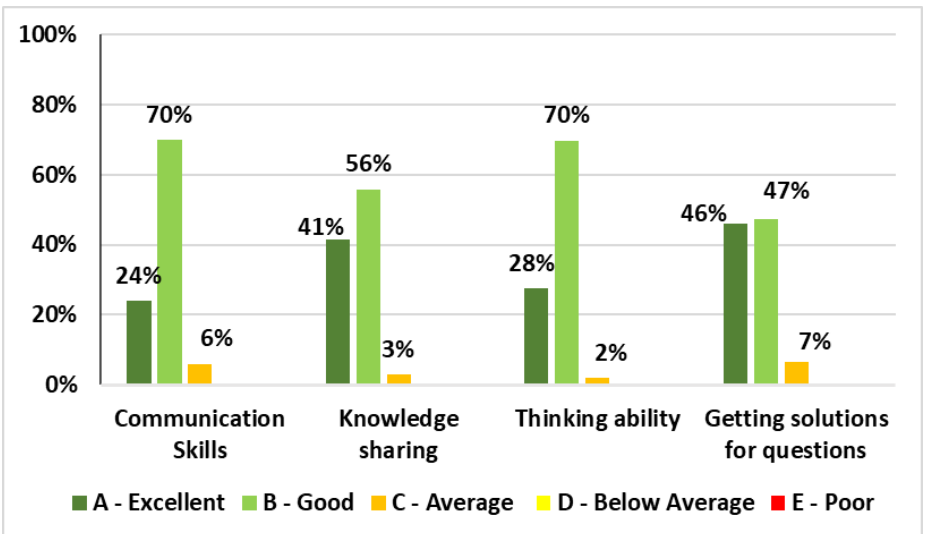

Fig.4: Feedback on Technical Assemblage

Fig.5 \& Fig.7 show average of Pre-class assessment results for two groups while Fig. 6 \& Fig.8 show Pre-class assessment results of the individual learner from group 1. Fig.5 shows the improvement in average score as $11.5 \%$ \& Fig.7 shows the improvement as $18.5 \%$ for the proposed method.

Fig.6 indicates the improvement in performance for most of the learners whereas the proposed method results in improvement in the performance of each and every learner (Fig.8)

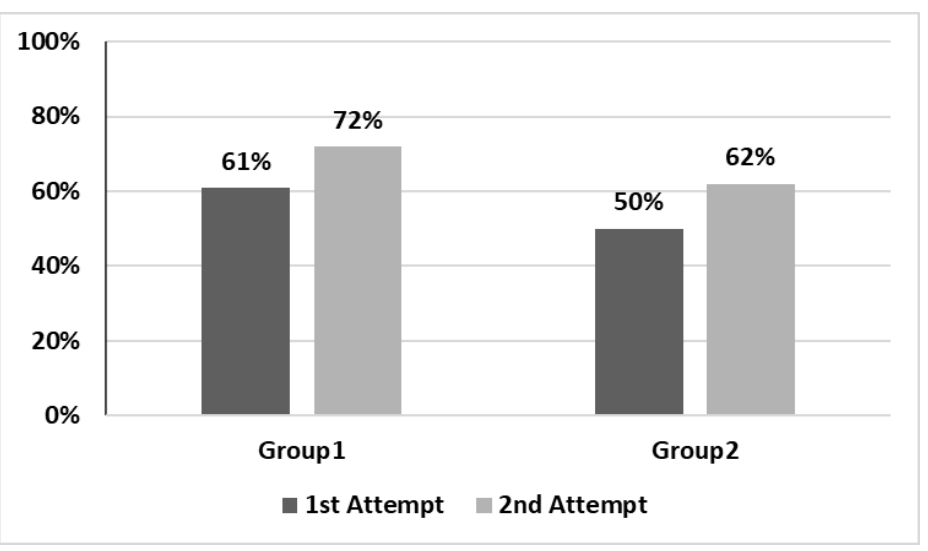

Fig.5: Pre-class assessment results [Conventional flipped classroom]

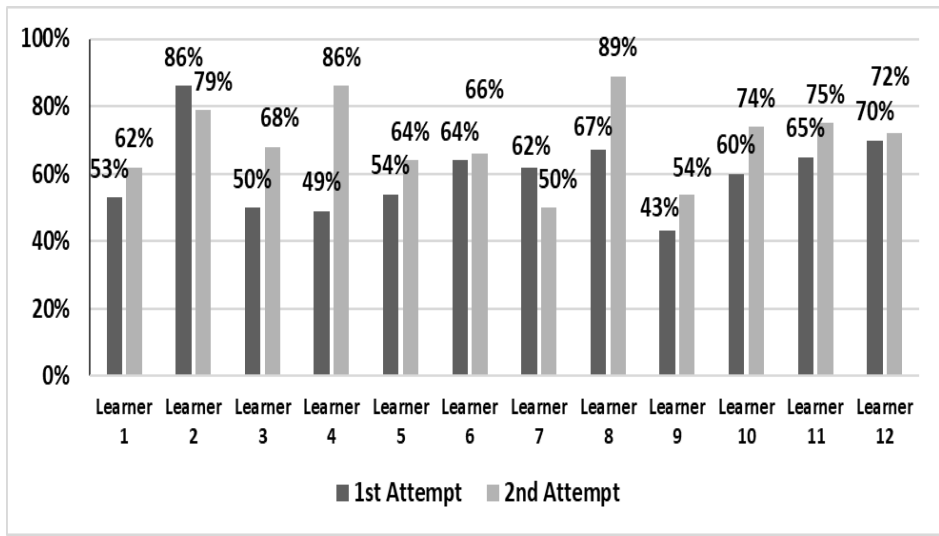

Fig.6: Pre-class assessment results of the individual learner [Conventional flipped classroom]

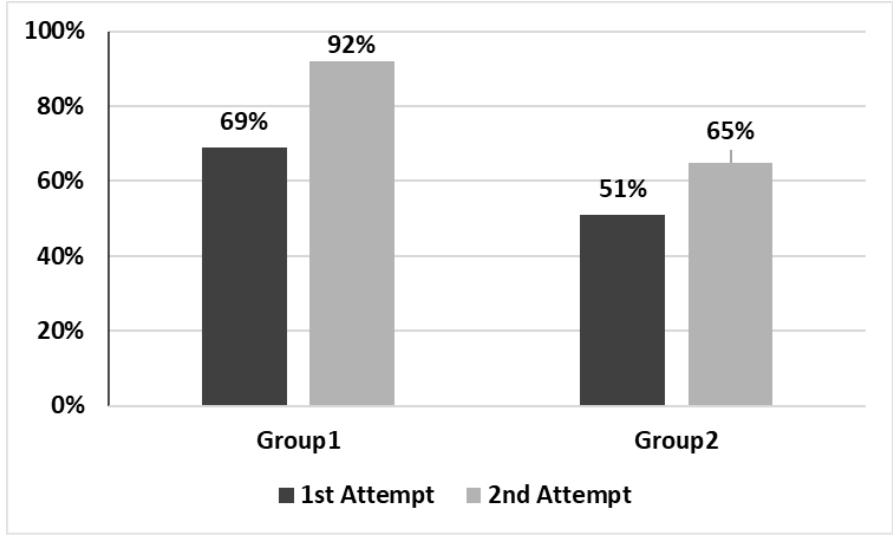

Fig.7: Pre-class assessment results [Proposed method]

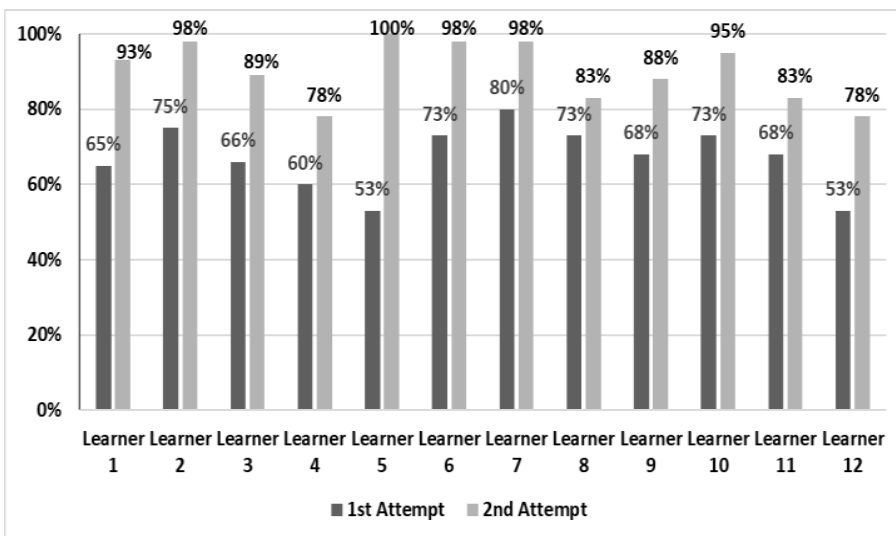

Fig.8: Pre-class assessment results of the individual learner [Proposed method] 


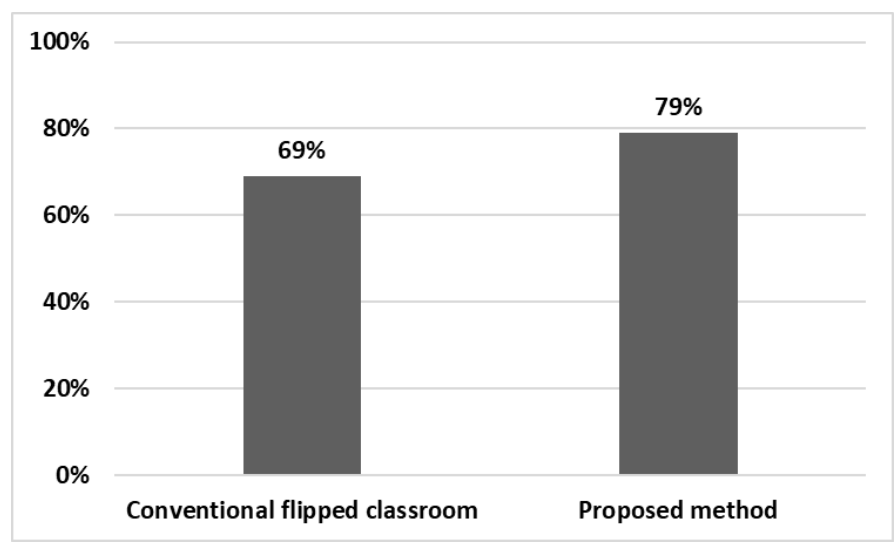

Fig.9: Post-class assessment results

Fig.9 shows the average score of Post class assessment results of the conventional flipped classroom and proposed method for a particular topic. Listed below are 2 questions from the CMOS fabrication post-class assessment.

1. In VLSI circuits resistors are commonly built using
a) Polysilicon
b) Silicided polysilicon
c) Metal
d) NWELL

2. Choose the techniques used to isolate active transistors in an Integrated Circuit
a) Field oxide
b) Channel stop implant
c) Shallow trench isolation
d) Gate oxide or thin oxide

The average score of learners for the conventional method is $69 \%$ and for the proposed method is $79 \%$. There is a $10 \%$ improvement with the proposed method which is significant.

\section{Benefits \& challenges}

The Technical Assemblage results in the following benefits. As described every learner gets an opportunity to lead a discussion on a topic with active participation being encouraged. Each discussion lasts for 1 hour and it is conducted on a daily basis. Assuming a one-month training program this would approximately result in twenty Technical Assemblage sessions. This ensures improvement in the ability to articulate one's understanding, ability to formulate questions and interact with a group.

One of the challenges in the proposed method is that it is effective for group sizes of 10 to 40 for effective learning. Another critical factor for the success of this method is that the observer should be knowledgeable with the ability to assess and guide the discussion.

\section{Conclusion \& future scope}

The Technical Assemblage as described was implemented in multiple training batches at ekLakshya and found to be effective. The analysis done by collecting the feedback from the learners was found to be satisfactory and clearly indicates that, this activity enhances both technical understanding and communication skills in a learner. Adding Technical Assemblage in the learning methodology of the conventional flipped classroom is beneficial with improvements in all the learners.

As discussed the topics for Technical Assemblage are chosen based on the most difficult questions from pre-class assessments. Continuous improvement in pre-class assessments based on the learning outcome is planned which will impact the breadth and depth of Technical Assemblage.

The results discussed in this paper are based on implementation of this method in multiple VLSI training batches of varied backgrounds. We believe it can be extended to other topics or other engineering fields as well.

\section{References}

1. Braseby, A.M., 2014. The Flipped Classroom. IDEA Paper\# 57. IDEA Center, Inc.

2. Hyman, M.R. and Sierra, J.J., 2016. Open-versus close-ended survey questions. Business Outlook, 14(2), pp.

3. Shraddha, B.H., Iyer, N.C., Kotabagi, S., Mohanachandran, P., Hangal, R.V., Patil, N., Eligar, S. and Patil, J., 2020. Enhanced Learning Experience by Comparative Investigation of Pedagogical Approach: Flipped Classroom. Procedia Computer Science, 172, pp.22-27.

4. Szparagowski, R., 2014. Exploring the Effectiveness of the Flipped Classroom.

5. Zainuddin, Z. and Halili, S.H., International Review of Research in Open and Distributed Learning. Flipped Classroom Research and Trends from Different Fields of Study, 17 (3).

6. Halili, S.H. and Zainuddin, Z., 2015. Flipping the classroom: What we know and what we don't. The online Journal of Distance Education and elearning, 3(1), pp.28-35.

7. Eppard, J. and Rochdi, A., 2017. A Framework for Flipped Learning. International Association for Development of the Information Society.

8. McCabe, A. and O'Connor, U., 2014. Studentcentred learning: the role and responsibility of the lecturer. Teaching in Higher Education, 19(4), pp.350359.

9. Bishop, J.L. and Verleger, M.A., 2013, June. The flipped classroom: A survey of the research. In ASEE national conference proceedings, Atlanta, GA (Vol. 30, No. 9, pp. 1-18).

10. Sabilah, I. and Manoy, J.T., 2018, January. The Use of Open-Ended Questions with Giving Feedback (OEQGF) for Effective Mathematic Learning. In Journal of Physics: Conference Series (Vol. 947, No. 1, p. 012032). IOP Publishing.

11. Worley, P., 2015. Open thinking, closed questioning: Two kinds of open and closed question. Journal of Philosophy in Schools, 2(2).

12. Hyman, M.R. and Sierra, J.J., 2016. Open-versus close-ended survey questions. Business Outlook, 14(2), pp.1-5. 